\title{
Application of plackett-burman design to benzylation of $o$-cresol with benzyl alcohol
}

\author{
M. Shahruzzaman ${ }^{1}$, D. Saha ${ }^{1 *}$, M. S. Rahman ${ }^{2}$ and M. S. Rahman ${ }^{2}$ \\ ${ }^{I}$ Department of Applied Chemistry and Chemical Engineering, University of Dhaka, Dhaka-1000, Bangladesh. \\ ${ }^{2}$ Institute of Leather Engineering and Technology, University of Dhaka, 44-50 Hazaribagh, Dhaka-1209, Bangladesh.
}

\begin{abstract}
Plackett-Burman design was employed to study the reaction of $o$-cresol with benzyl alcohol in the presence of anhydrous aluminium chloride as catalyst for screening variables. The variables chosen for the investigation were temperature, molar ratio of $o$-cresol to benzyl alcohol, amount of anhydrous $\mathrm{AlCl}_{3}$ catalyst (\% by wt. of $o$-cresol), addition time (ta h), stirring time (ts h), stirring speed (rpm). Among these variables temperature, molar ratio of $o$-cresol to benzyl alcohol and amount of anhydrous $\mathrm{AlCl}_{3}$ were found to be important. A set of trials was planned according to a 3 factor 2-level Yates pattern experimental design with 2 replicates and the center point trial with 4 replicates. The critical response was the yield of benzyl $o$-cresol. Main effects as well as two- and three- factor interaction effects were statistically significant. A polynomial model was developed and the adequacy of the suggested model was checked up.
\end{abstract}

Keywords: Plackett-burman; o-cresol; Benzyl alcohol; Catalyst (Aluminium chloride); Variables; Polynomial model

\section{Introduction}

Friedel Craft's reaction as invented more than hundred years ago, still the reaction is in the attention of many investigators. This is because of the fact that the products of the reaction have found wide practical utilization in different fields. Among the alkylation processes, alkylation of cresols is very important. Alkylated cresols and their derivatives are outstanding antioxidants in fuels, lubricating oils and polymeric materials (Shreve and Brink, 1977; Lebedev, 1984; Ravikovich, 1964; Filbey et. al., 1985). Some of their derivatives are strong herbicides, bactericides and insecticides (Nemetkin et. al., 1951; Belov and Isagulyants, 1964; Melnikov et. al., 1954). Alkylation of isomeric cresols has been carried out by cycloalkenes (Topchiev et. al., 1964; Saha et. al., 1994, 1995, 1996, 1997, 1998, 2000; Saha and Ghosh, 1989) and cycloalcohols (Abdurasuleba and Israilova, 1962; Abdurasuleba et. al., 1965, 1969; Ismailov, 1970; Saha and Roy, 1988, 1989, 1990, 1992; Saha and Ghosh, 1990; Saha and Badruzzaman, 1990; Saha et. al., 1995, 1997, 2000, 2004) by several authors. Statistical studies have been made on the alkylation of cresols with alcohols and olefins by our research group (Palma et. al., 2007; M. Ismail et. al., 2007;
Alam et. al., 2008; Alam et. al., 2008). But studies on the statistical designs of benzylation of $o$-cresol with benzyl alcohol are absent.

Present work deals with the benzylation of $o$-cresol with benzyl alcohol in the presence of anhydrous aluminium chloride as catalyst by means of statistical experimental design. The aim of the present investigation is to screen variables by Plackett-Burman design and develop a mathematical model by using a $2^{3}$ factorial design that describe the process of alkylation of $o$-cresol with benzyl alcohol in the presence of anhydrous aluminium chloride as catalyst (Clausen and Matson, 1978).

\section{Materials and methods}

The reactions were carried out in a three-necked round bottomed flask fitted with a condenser, a thermometer, a dropping funnel and a magnetic stirrer. $o$-Cresol and anhydrous aluminium chloride mixture was heated to the desired temperature. Benzyl alcohol was introduced into the mixture gradually over a certain period of time (time of addition) with constant stirring. After the complete addition 
of benzyl alcohol the reaction mixture was stirred for an extended period of time (time of stirring) at the same temperature. The reaction mass was then cooled to room temperature, dissolved in a solvent (toluene), then washed with distilled water several times and distilled at atmospheric pressure. Unreacted reactants and solvent were distilled off and the yield was expressed as a percentage of theory. The residual product was finally distilled and its structure was elucidated by physico-chemical and spectral means (UV, IR, $\left.{ }^{1} \mathrm{HNMR},{ }^{13} \mathrm{CNMR}\right)$.

\section{Results and discussion}

All experiments were planned according to experimental design (Clausen and Matson, 1978). The critical response of interest was yield of benzyl $o$-cresol.

Six potential variables were considered to have an influence on the yield and selected for screening experiments. These factors and the selected experimental levels are listed in Table I. Since there were six factors, a 12-trial Plackett-Burman design would be suitable. This design had a nominal capacity of 11 variables or factors. The five unassigned factors $\left(\mathrm{X}_{7}\right.$ through $\mathrm{X}_{11}$ ) were used in the computation to get some measure of the experimental error. The experimental design and the calculations are illustrated in Table II. Each of the 12 trials of the design is listed in horizontal lines. The vertical columns labeled $X_{1}$ through $X_{11}$ indicated the label of the factor in each trial. In regard to the design, in the 12 trials each factor was at a high + level for 6 trials and at a low (-) level for 6 trials. The yield for each trial was indicated in the Y column on the right.
The Sum +'s line was then computed by adding the yield values for all lines where the factor was at a + level. (Example: $\mathrm{X}_{1}$ factor $69.2+70.1+79.6+72.1+57.3+70.8$ $=419.1)$. This operation was continued across the table for all factors, including the five unassigned factors. In a similar way, the Sum-'s line was computed. The next line simply total the Sum +'s and Sum-'s to check to the arithmetic. The next line is the difference between the Sum +'s and the Sum -'s for each factor. This represented the total difference in yield for the six trials where the factor was at the plus level, from the six trials where the factor was at a minus leve 1 . The last line represented the average effects of the factor at the plus level and was computed by dividing the difference by 6 , the number of plus signs in the column. The absolute values of the calculated factor effects related to their relative importance. $X_{1}$, temperature was clearly the most important variable. In order to determine whether a factor effect was significant, experimental error must be considered. The minimum value for factor effect to be significant was computed using the five unassigned factor effects $X_{7}$ through $X_{11}$. Each unassigned factor effect was squared, totaled, divided by 5 , the number of unassigned factors. The square root of this number multiplied by a magic number gave the minimum significant factor effect [MIN]. The magic number used in this computation came from a table of probability points of the t-distribution corresponding to five degrees of freedom (five unassigned factors) and the $95 \%$ confidence level. What this meant was that if we used 3.44 as the cut off point, we had a 95 out of 100 chance of being correct in our selection of the significant factor effects. Using these criteria then, three variables- temperature, molar ratio of $o$-cresol to benzyl alcohol, amount of catalyst (anhydrous aluminium

Table I. Candidate Variables

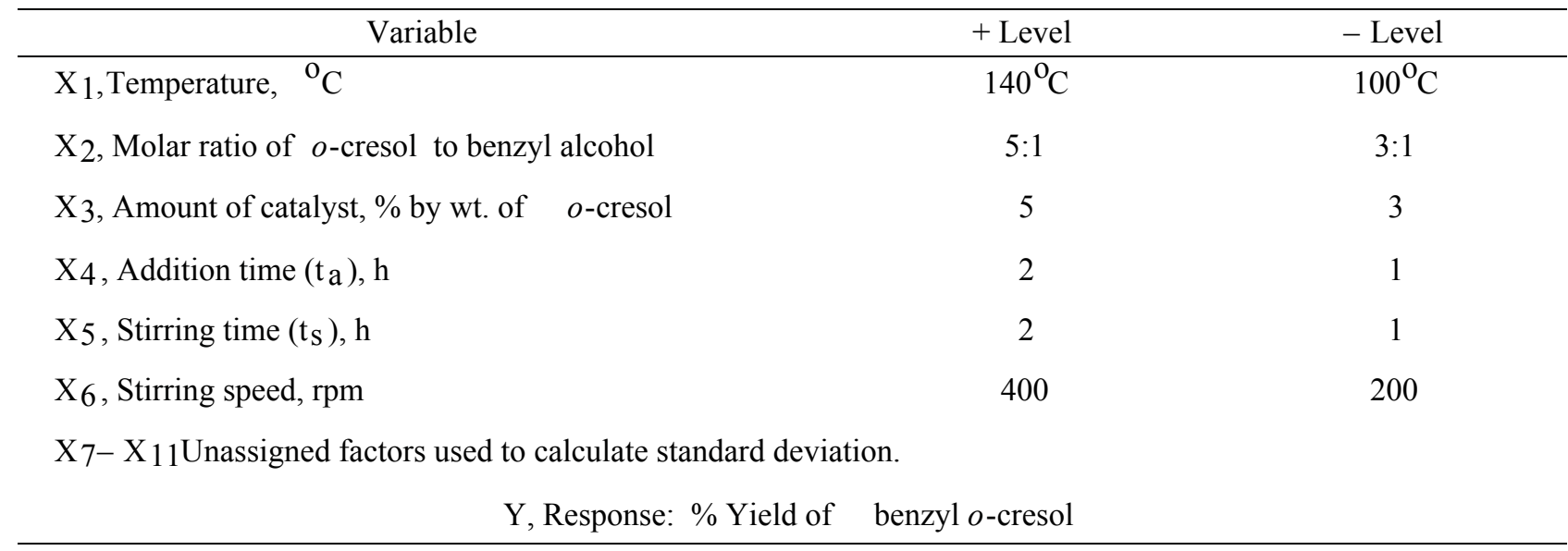




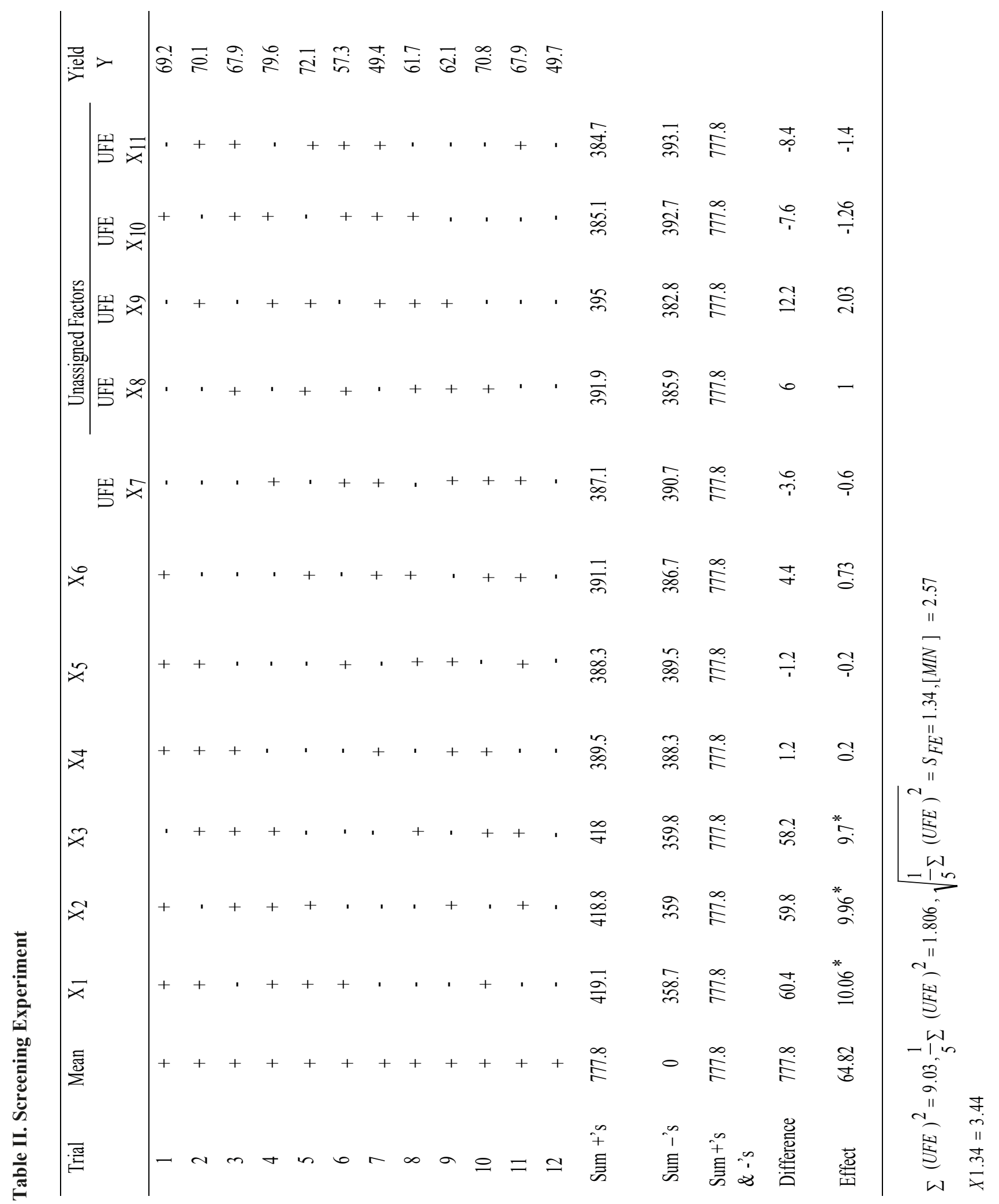


Table III. Process variables and Response

\begin{tabular}{|c|c|c|c|}
\hline \multirow[b]{2}{*}{ Variable } & \multirow[b]{2}{*}{ Low $(-)$} & \multicolumn{2}{|l|}{ Range } \\
\hline & & Mid (0) & High $(+)$ \\
\hline $\mathrm{X}_{1}$, Temperature $\left({ }^{\circ} \mathrm{C}\right)$ & 100 & 120 & 140 \\
\hline $\mathrm{X}_{2}$, Molar ratio of $o$-cresol to benzyl alcohol & $3: 1$ & $4: 1$ & $5: 1$ \\
\hline $\begin{array}{r}\mathrm{X}_{3}, \text { Amount of catalyst, } \% \text { by wt. of } \quad o \text {-cresol } \\
\text { Y, Response : } \% \text { Yield of }\end{array}$ & $\begin{array}{c}3 \\
\text { benzyl } o \text {-cresol }\end{array}$ & 4 & 5 \\
\hline
\end{tabular}

chloride) were found to be important and investigated further. Addition time of benzyl alcohol to the $o$-cresol $-\mathrm{AlCl}_{3}$ mixture and stirring time after the addition of benzyl alcohol either had no effect or an effect so small that it was obscured by the experimental error and interaction effects. Stirring speed did not have any influence on the reaction rate. After determining which of the candidate variables were really significant, the next objective was to develop a mathematical model of the process using Yates pattern experimental design (Clausen and Matson, 1978). We considered three key process variables and one critical response- yield of benzyl $o$-cresol. Table III lists the experimental ranges of the yielding 16 trials. In order to check the lack of fit due to curvature, additional trial was made at the midpoint level of each factor. The difference between the average centre point value and the overall average of the design points indicated the severity of curvature. Table IV illustrates the two level 3 -factor design with the factors in coded form. The experimental runs for Trial 1 through 8 were run in duplicate; Trial 9, the centre point trial was run four times, interspersed throughout the experimental run. The results of these experiments are listed in Table $\mathrm{V}$. The average yield, the range and the variance were calculated for each trial. The

Table IV. Experimental Design

\begin{tabular}{ccccc}
\hline Trial No. & Replicates & Temperature, & $\begin{array}{c}\text { Design } \\
\text { Molar ratio, }\end{array}$ & $\begin{array}{c}\text { Amount of } \\
\text { catalyst, X 3 }\end{array}$ \\
\hline 1 & & $\mathrm{X}_{1}$ & $\mathrm{X}_{2}$ & - \\
\hline 2 & 2 & - & - & - \\
3 & 2 & + & - & - \\
4 & 2 & - & + & - \\
5 & 2 & + & + & + \\
6 & 2 & - & - & + \\
7 & 2 & - & + & + \\
8 & 2 & + & + & + \\
9 & 4 & 0 & 0 & 0 \\
\hline
\end{tabular}

variables temperature, molar ratio of $o$-cresol to benzyl alcohol, amount of catalyst (anhydrous aluminium chloride). The values of $t_{a}, t_{s}$ and stirring speed were set to the constant values of $2 \mathrm{~h}, 1 \mathrm{~h}$ and $300 \mathrm{rpm}$, respectively. The experimental design used was Yates pattern, 3 factor two level factorial; there were $2^{3}$ i.e. eight trials. Since the basic $2^{3}$ factorial design involved eight trials, each was run in duplicate variance, which is an estimate of dispersion of data, was calculated by the following formula:

For Trial 1, variance $=\mathrm{S}_{1}^{2}$

$$
=\frac{(47.6-48.1)^{2}+(48.6-48.1)^{2}}{2-1}=0.5
$$


So,

For Trial 2, variance $=\mathrm{S} 22=0.72$

For Trial 3, variance $=\mathrm{S} 32=0.98$

For Trial 4 , variance $=\mathrm{S} 42=1.28$

For Trial 5 , variance $=\mathrm{S} 52=0.72$

For Trial 6, variance $=\mathrm{S} 62=1.28$

For Trial 7, variance $=\mathrm{S} 72=0.98$

For Trial 8 , variance $=\mathrm{S} 82=1.62$

Variance $=\mathrm{S}^{2}=\frac{\left(Y_{1}-\bar{Y}\right)^{2}+\left(Y_{2}-\bar{Y}\right)^{2}+\ldots \ldots \ldots \ldots \ldots \ldots . .+\left(Y_{n}-\bar{Y}\right)^{2}}{n-1}$

where $Y=$ response value,

$\bar{Y}=$ average or mean of response value

and $n=$ number of observations

For Trial 9, variance $=\mathrm{S}_{9}{ }^{2}$

$=\frac{(63.5-64.3)^{2}+(63.9-64.3)^{2}+(64.7-64.3)^{2}+(65.1-64.3)^{2}}{4-1}$

$=0.53$
The variances calculated for each trial were then used in the calculation of a weighted average of the individual variances for each trial

$$
\begin{aligned}
& \text { Pooled variance }=\mathrm{S}_{\text {pooled }}^{2} \\
& =\frac{\left(n_{1}-1\right)\left(S_{1}{ }^{2}\right)+\left(n_{2}-1\right)\left(S_{2}{ }^{2}\right)+\ldots \ldots \ldots \ldots \ldots+\left(n_{K}-1\right)\left(S_{K}{ }^{2}\right)}{\left(n_{1}-1\right)+\left(n_{2}-1\right)+\ldots \ldots \ldots .+\left(n_{K}-1\right)} \\
& =0.879
\end{aligned}
$$

The pooled standard deviation is the square root of the pooled variance:

Standard deviation $_{\text {pooled }}=\sqrt{\mathrm{S}_{\text {pooled }}^{2}}=\sqrt{0.879}=0.937$

The pooled standard deviation was used to calculate the minimum observed effect that was statistically significant. The computation analysis for this experiment is shown in Table VI. The design matrix was supplemented with a computation matrix, which was used to detect any interaction effect.

This computation matrix was generated by simple algebraic multiplication of the coded factor levels. In Trial $1, \mathrm{X}_{1}$ was minus, $\mathrm{X}_{2}$ was minus, therefore, $\mathrm{X}_{1} \mathrm{X}_{2}$ was plus; in Trial 2, $\mathrm{X}_{1}$

Table V. Results of three-factor experiment

\section{Results}

Trial No.

Yield

\begin{tabular}{cccccc} 
& $\mathrm{Y}_{1}$ & $\mathrm{Y}_{2}$ & $\bar{Y}$ & Range & Variance \\
\hline 1 & 47.6 & 48.6 & 48.1 & 1 & 0.50 \\
2 & 58.1 & 59.3 & 58.7 & 1 & 0.72 \\
3 & 62.5 & 63.9 & 63.2 & 1 & 0.98 \\
4 & 70.1 & 71.7 & 70.9 & 2 & 1.28 \\
5 & 59.6 & 60.8 & 60.2 & 1 & 0.72 \\
6 & 70.8 & 72.4 & 71.6 & 2 & 1.28 \\
7 & 68.0 & 69.4 & 68.7 & 1 & 0.98 \\
8 & 77.8 & 79.6 & 78.7 & 2 & 1.62 \\
9 & 63.5 & 63.9 & & & 0.53 \\
& 64.7 & 65.1 & 64.3 & & \\
\hline
\end{tabular}


was plus, $X_{2}$ was minus, therefore $X_{1} X_{2}$ was minus. The column at the far right of the table is the average yield for each trial. The sum +'s row was generated by totaling the response values on each row with a plus for each column. For $\mathrm{X}_{1}$ factor, $58.7+70.9+71.6+78.7=279.9$. In the similar manner the sum -'s row was generated. The sum of these two rows should equal the sum of all the average responses and was included as a check on the calculations. The difference row represented the difference between the responses in the four trials when the factor was at a high level and the responses in the four trials when the factor was at a low level. The effect was then calculated by dividing the difference by the number of plus signs in the column. In the first column, labeled mean, the effect value was the mean or average of all data points. The average of the centre point runs, Trial 9, was then subtracted from the mean effect to give a measure of curvature.

The minimum significant factor effect [MIN] and the minimum significant curvature effect [MINC] were again derived from t-test significance criteria.
The relationships are:

$$
\begin{aligned}
& {[\mathrm{MIN}]=\mathrm{t} . \mathrm{s} \text { and }} \\
& {[\mathrm{MINC}]=\mathrm{t} . \mathrm{s}}
\end{aligned}
$$

where $\mathrm{t}=$ appropriate value from " $\mathrm{t}$ - table",

$\mathrm{s}=$ pooled standard deviation,

$\mathrm{m}=$ number of plus signs in column,

$\mathrm{k}=$ number of replicates in each trial

and $\quad \mathrm{c}=$ number of centre points.

The $t$ value of 2.20 is from the Students" " $t$ " table for the $95 \%$ confidence level and 11 degrees of freedom (Davies, 1979). The degrees of freedom resulted from eight trials with two replicates and one trial with four replicates.

Table VI. Computation matrix for three factor experiment

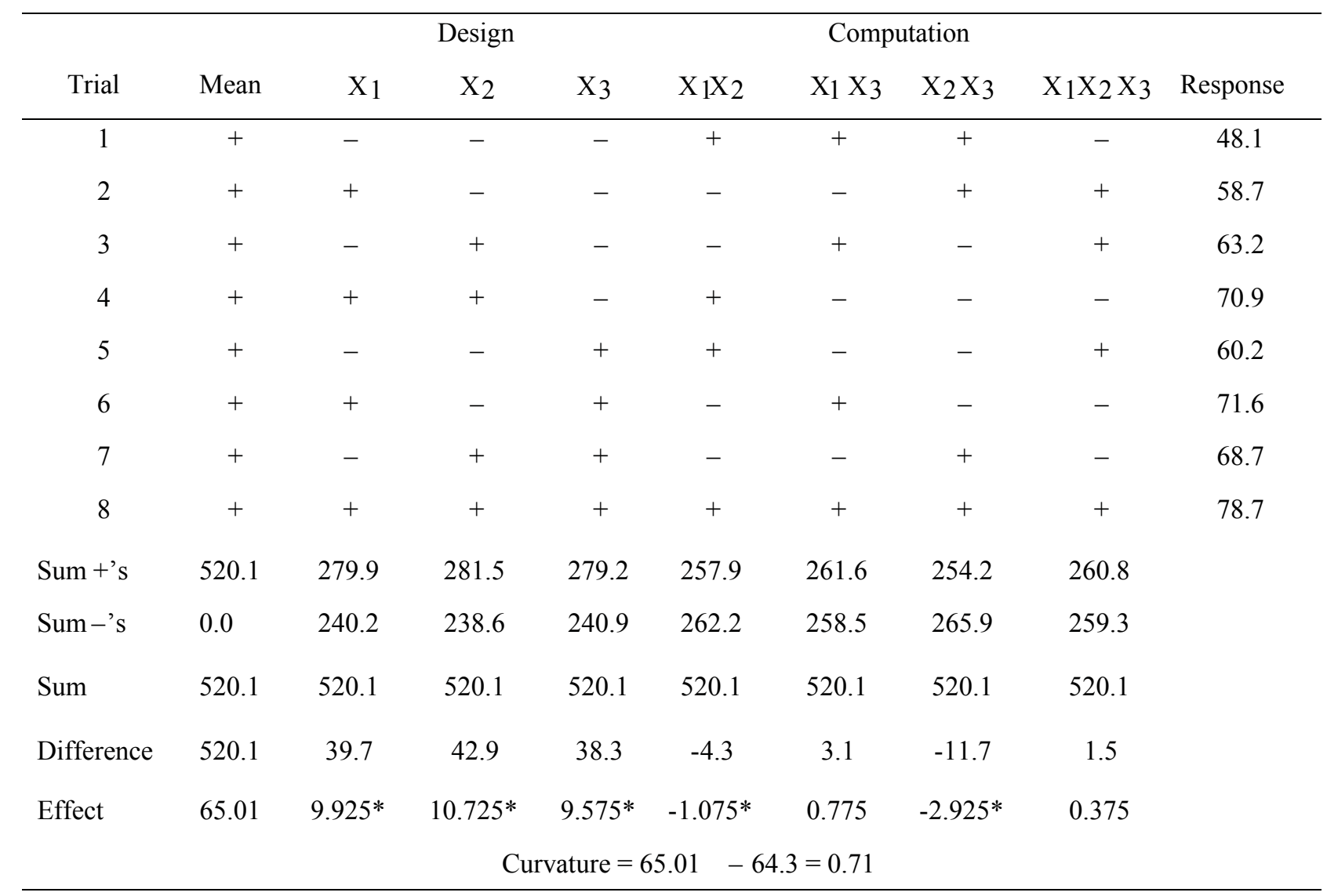


Degrees of freedom $=8(2-1)+1(4-1)=11$

The calculations for the minimum significant effects were as follows:

$[\mathrm{MIN}]=1.0307$ and $[\mathrm{MINC}]=1.152$

Applying these criteria to the calculated effects, it was seen that the effects of temperature $\left(\mathrm{X}_{1}\right)$, molar ratio of $o$-cresol to benzyl alcohol $\left(\mathrm{X}_{2}\right)$, amount of aluminium chloride $\left(\mathrm{X}_{3}\right)$, interaction between temperature and molar ratio of $o$-cresol to benzyl alcohol $\left(\mathrm{X}_{1} \mathrm{X}_{2}\right)$, interaction between molar ratio of $o$-cresol to benzyl alcohol and amount of anhydrous aluminium chloride $\left(\mathrm{X}_{2} \mathrm{X}_{3}\right)$ were significant. There was no significant curvature effect.

These results were expressed as a mathematical model using a first order polynomial. The values for the co-efficients were one half the factor effects listed in Table 6 since these were based upon coded levels +1 and -1 that differed by two units.

$\mathrm{Y}=65.01+4.9625 \mathrm{X}_{1}+5.362 \mathrm{X}_{2}+4.787 \mathrm{X}_{3}-0.537 \mathrm{X}_{1} \mathrm{X}_{2}$ $-1.462 \mathrm{X}_{2} \mathrm{X}_{3}$

In this equation, the factors were expressed in coded units. These were converted into real units by substituting:

$$
\begin{aligned}
& \text { for temperature } \mathrm{T}\left({ }^{0} \mathrm{C}\right), \mathrm{X}_{1}=\frac{T-120}{20} \\
& \text { for molar ratio (m:1), } \mathrm{X}_{2}=\frac{m-4}{1} \\
& \text { for the amount of catalyst }(\mathrm{y}), \mathrm{X}_{3}=\frac{y-4}{1}
\end{aligned}
$$

These substitutions yielded the following final expression:

$$
\begin{aligned}
\mathrm{Y}=- & 41.614+0.355 \mathrm{~T}+14.426 \mathrm{~m}+10.635 \mathrm{y}- \\
& 0.0268 \mathrm{Tm}-1.462 \mathrm{my}
\end{aligned}
$$

For Trial 1 , temperature $(\mathrm{T})=100{ }^{\circ} \mathrm{C}$, molar ratio of $o$-cresol to benzyl alcohol $(\mathrm{m}: 1)=3: 1$ and the amount of catalyst $(\mathrm{y})=$ $3 \%$ by wt. of $o$-cresol. Therefore, yield calculated from the derived model,

$$
\begin{aligned}
\mathrm{Y}_{\text {(cal.) }}= & -41.614+0.355 \times 100+14.426 \times 3+ \\
& 10.635 \times 3-0.0268 \times 100 \times 3-1.462 \times 3 \times 3 \\
= & 47.87
\end{aligned}
$$

Experimental average yield of the Trial 1, $\mathrm{Y}_{(\text {exp.) }}=48.1$.

Hence, deviation $=0.23$ and percentage deviation $=0.478$.

Table VII gives a comparison of the experimentally determined yield of benzyl $o$-cresol (each value is the average of two replicates) with the predicted yield from the derived

\begin{tabular}{|c|c|c|c|c|}
\hline \multirow[t]{2}{*}{ Trial } & \multicolumn{2}{|c|}{$\%$ yield of benzyl $o$-cresol } & \multirow[t]{2}{*}{ Deviation } & \multirow{2}{*}{$\begin{array}{c}\text { Percentage } \\
\text { deviation }\end{array}$} \\
\hline & Experimental & Predicted & & \\
\hline 1 & 48.1 & 47.87 & 0.23 & 0.478 \\
\hline 2 & 58.7 & 58.85 & -0.15 & -0.255 \\
\hline 3 & 63.2 & 62.59 & 0.61 & 0.965 \\
\hline 4 & 70.9 & 71.43 & -0.53 & -0.747 \\
\hline 5 & 60.2 & 60.369 & -0.169 & -0.280 \\
\hline 6 & 71.6 & 71.353 & 0.247 & 0.345 \\
\hline 7 & 68.7 & 69.24 & -0.54 & -0.786 \\
\hline 8 & 78.7 & 78.08 & 0.62 & 0.787 \\
\hline
\end{tabular}
equation. The discrepancies between the experimental and calculated values did not exceed $0.965 \%$.

The summarized results of the reaction of $o$-cresol with benzyl alcohol in the presence of anhydrous aluminium chloride as catalyst have been shown in Table VIII and Table IX.

Table VII. Experimental average yield and calculated yield 
Table VIII. Alkylation of $o$-cresol with benzyl alcohol in presence of anhydrous aluminium chloride

\begin{tabular}{|c|c|c|c|c|c|c|c|}
\hline \multirow{2}{*}{$\begin{array}{l}\text { Exp. } \\
\text { No. }\end{array}$} & \multirow[b]{2}{*}{$\begin{array}{c}\text { Temperature, } \\
{ }^{\circ} \mathrm{C}\end{array}$} & \multirow[b]{2}{*}{$\begin{array}{c}\text { Molar ratio of } \\
o \text {-cresol to } \\
\text { benzyl } \\
\text { alcohol }\end{array}$} & \multirow[b]{2}{*}{$\begin{array}{c}\text { Amount } \\
\text { of } \\
\text { catalyst, } \\
\% \text { by wt. } \\
\text { of } \\
o \text {-cresol }\end{array}$} & \multirow[b]{2}{*}{$\begin{array}{l}\text { Addition } \\
\text { time }(\mathrm{t} \mathrm{a}), \mathrm{h}\end{array}$} & \multirow[b]{2}{*}{$\begin{array}{l}\text { Stirring } \\
\text { time }\left(t_{\mathrm{s}}\right), \mathrm{h}\end{array}$} & \multirow[b]{2}{*}{$\begin{array}{l}\text { Stirring } \\
\text { speed, } \\
\text { rpm }\end{array}$} & \multirow[b]{2}{*}{$\begin{array}{l}\% \text { yield of } \\
\text { benzyl } o- \\
\text { cresol }\end{array}$} \\
\hline & & & & & & & \\
\hline 1 & 140 & $5: 1$ & 3 & 2 & 2 & 400 & 69.2 \\
\hline 2 & 140 & $3: 1$ & 5 & 2 & 2 & 200 & 70.1 \\
\hline 3 & 100 & $5: 1$ & 5 & 2 & 1 & 200 & 67.9 \\
\hline 4 & 140 & $5: 1$ & 5 & 1 & 1 & 200 & 79.6 \\
\hline 5 & 140 & $5: 1$ & 3 & 1 & 1 & 400 & 72.1 \\
\hline 6 & 140 & $3: 1$ & 3 & 1 & 2 & 200 & 57.3 \\
\hline 7 & 100 & $3: 1$ & 3 & 2 & 1 & 400 & 49.4 \\
\hline 8 & 100 & $3: 1$ & 5 & 1 & 2 & 400 & 61.7 \\
\hline 9 & 100 & $5: 1$ & 3 & 2 & 2 & 200 & 62.1 \\
\hline 10 & 140 & $3: 1$ & 5 & 2 & 1 & 400 & 70.8 \\
\hline 11 & 100 & $5: 1$ & 5 & 1 & 2 & 400 & 67.9 \\
\hline 12 & 100 & $3: 1$ & 3 & 1 & 1 & 200 & 49.7 \\
\hline
\end{tabular}

Table IX. Alkylation of $o$-cresol with benzyl alcohol in presence of anhydrous aluminium chloride

\begin{tabular}{ccccccc}
\hline $\begin{array}{c}\text { Expt. } \\
\text { No. }\end{array}$ & $\begin{array}{c}\text { Temperature, } \\
{ }^{\circ} \mathrm{C}\end{array}$ & $\begin{array}{c}\text { Molar ratio } \\
\text { Of } o \text {-cresol to } \\
\text { benzyl alcohol }\end{array}$ & $\begin{array}{c}\text { Amount of } \\
\text { aluminium } \\
\text { chloride } \\
\text { \% by wt. of } \\
o \text {-cresol }\end{array}$ & $\begin{array}{c}\text { Addition } \\
\text { time }\left(\mathrm{t}_{\mathrm{a}}\right), \mathrm{h}\end{array}$ & $\begin{array}{c}\text { Stirring } \\
\text { time }\left(\mathrm{t}_{\mathrm{s}}\right), \mathrm{h}\end{array}$ & $\begin{array}{c}\text { \% yield of } \\
\text { benzyl } o \text { - } \\
\text { cresol }\end{array}$ \\
\hline 1 & 100 & $3: 1$ & 3 & 2 & 1 & 48.1 \\
2 & 140 & $3: 1$ & 3 & 2 & 1 & 58.7 \\
3 & 100 & $5: 1$ & 3 & 2 & 1 & 63.2 \\
4 & 140 & $5: 1$ & 3 & 2 & 1 & 70.9 \\
5 & 100 & $3: 1$ & 5 & 2 & 1 & 60.2 \\
6 & 140 & $3: 1$ & 5 & 2 & 1 & 71.6 \\
7 & 100 & $5: 1$ & 5 & 2 & 1 & 68.7 \\
\hline
\end{tabular}


The yield of benzylo-cresol increased with the increase of temperature (Expt. No. 1,2; 3,4; 5,6 and 7,8), molar ratio of $o$-cresol to benzyl alcohol (Expt. No. 1,3; 2,4; 5,7 and 6,8) and amount of catalyst (Expt. No. 1,5; 2,6; 3,7 and 4,8). Thus the best yield (78.7\%) of benzylo-cresol was obtained under following conditions: temperature $=140^{\circ} \mathrm{C}$, molar ratio of $o$-cresol to benzyl alcohol $=5: 1$, amount of catalyst $=5 \%$ by wt. $o$-cresol, time of addition $=2 \mathrm{~h}$ and time of stirring $=1 \mathrm{~h}$.

\section{Spectral studies (UV, IR, ${ }^{1} \mathrm{H}$ NMR, ${ }^{13} \mathrm{C}$ NMR spectrum) of benzyl $o$-cresol}

Mixture of two isomers of benzyl $o$-cresol, (I) and (II) was obtained by the reaction of $o$-cresol with benzylalcohol according to the following equation:

Benzyl $o$-cresol in methanol solution absorbed strongly at $\lambda_{\max }=275.0 \mathrm{~nm}$ in the UV-spectrum (Fig. 1).
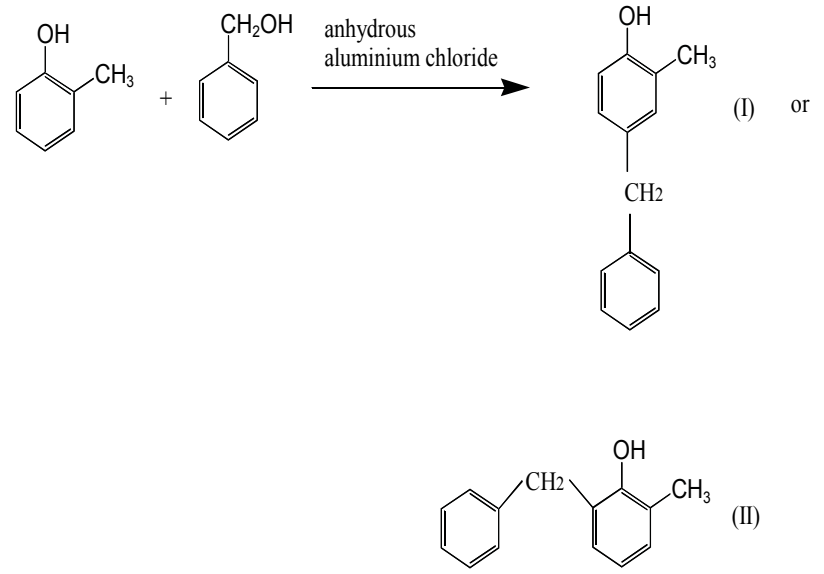

Positions of the characteristic absorption of the product in the IR-spectrum (Fig. 2) are shown in Table X.

Table X. The IR spectrum of benzyl o-cresol

$\begin{array}{ll}3532 \mathrm{~cm}^{-1} & \text {-OH group } \\ 3027 \mathrm{~cm}^{-1} & \text { Aromatic }=\mathrm{C}-\mathrm{H} \text { stretching } \\ 2920 \mathrm{~cm}^{-1} & \text { Saturated } \mathrm{C}-\mathrm{H} \text { stretching } \\ 1594 \mathrm{~cm}^{-1} & \text { Aromatic ring } \mathrm{C}=\mathrm{C} \text { stretching } \\ 800-900 \mathrm{~cm}^{-1} & 1,2,4-\text { tri substituted benzene ring } \\ 700 \& 754 \mathrm{~cm}^{-1} & 1,2,3 \text { - tri substituted benzene ring }\end{array}$

Table XI. The ${ }^{1} \mathrm{H}$ NMR spectrum of benzyl $o$-cresol

\begin{tabular}{lc}
\hline \multicolumn{1}{c}{ Observed signals of the protons } & Chemical shift in $\delta$ ppm \\
\hline Two benzene ring protons & $6.5-7.3$ \\
Two protons of - $\mathrm{CH}_{2}$ - on benzyl group & $3.8-4.0$ \\
One proton on the - $\mathrm{OH}$ group & $4.7-4.9$ \\
Three protons of $-\mathrm{CH} 3$ group & $2.0-2.3$
\end{tabular}



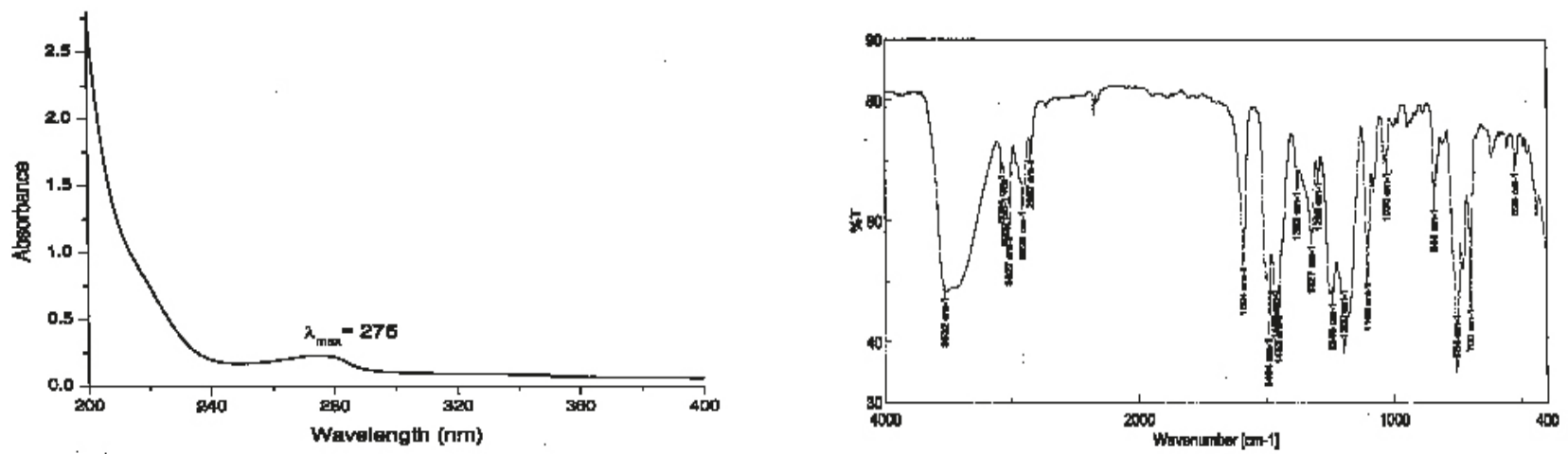

Fig. 1. The UV spectrum (in methanol) of benzyl $o$-cresol

Fig. 2. The IR spectrum of benzyl $o$-cresol

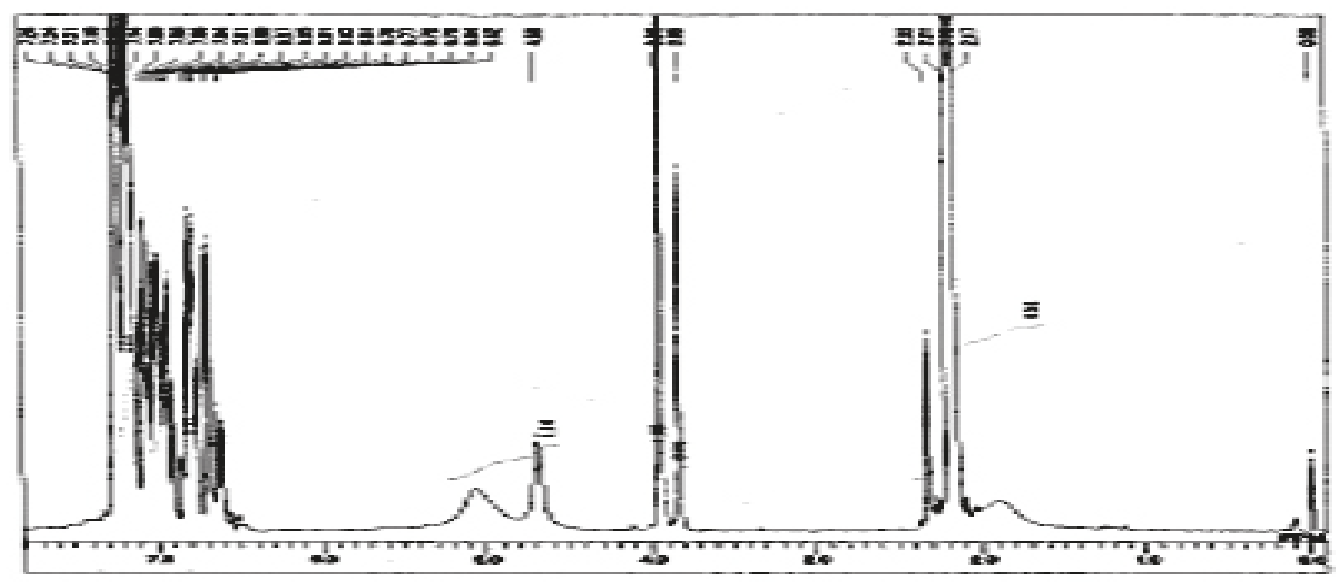

Fig. 3. The ${ }^{1}$ H NMR spectrum of benzyl $o$-cresol in solvent..

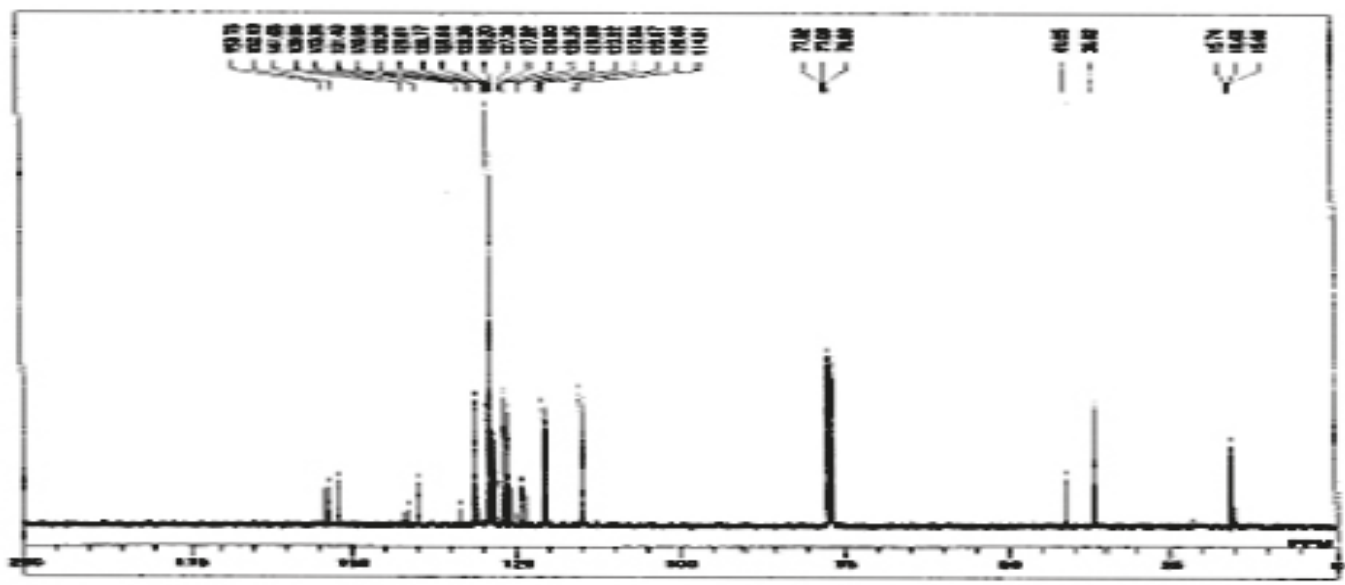

Fig. 4. The ${ }^{13} \mathrm{C}$ NMR-spectrum of benzyl $o$-cresol in solvent.. 
The ${ }^{1} \mathrm{H}$ NMR spectrum of the product showed peaks whose $\delta$ ppm values are represented in Fig. 3 and chemical shifts of the protons have been recorded in Table XI.

In the ${ }^{13} \mathrm{C}$ NMR spectrum, peaks of all the aliphatic carbons were observed at $\delta=15.60-41.05$, while peaks at $\delta=$ 114.91-153.78 accounted for the aromatic carbons (Fig. 4).

The product was a mixture of two isomers and gave two sets of ${ }^{1} \mathrm{H}$ and ${ }^{13} \mathrm{C}$ NMR peaks. By comparing the peaks intensity of certain protons (eg. $\mathrm{CH}_{2}$ ), the ratio of the two isomers, 1: 11 or 11:1 was found to be 2.27 .

Benzyl $o$-cresol had b.p. $=310{ }^{\circ} \mathrm{C}, n_{D}{ }^{20}=1.5910$ and $d_{4}^{20}=$ $1.0943\left(\mathrm{Mr}_{\mathrm{D}}\right.$ Found: 61.175; calc: 61.179).

\section{Conclusions}

By means of Placket-Burman design it was shown that temperature, molar ratio of $o$-cresol to benzyl alcohol and amount of catalyst were the significant variables of the reaction. A $2^{3}$ Yates pattern design gave mathematical model to predict the yield. The highest experimental yield was found to be $78.7 \%$. the experimental settings were temperature, $140^{\circ} \mathrm{C}$; molar ratio of $o$-cresol to benzyl alcohol, 5:1; amount of $\mathrm{AlCl}_{3}, 5 \%$ by wt. of $o$-cresol; addition time, $2 \mathrm{~h}$ and stirring time, $1 \mathrm{~h}$. The predicted yield was $78.08 \%$. The difference between the experimental and estimated yields was negligible.

\section{References}

Abdurasuleba AR and Israilova ShA (1962), Condensation of $o$-cresol with cyclohexanol, Zh. Obsh. Khim. 32(3): 704-706.

Abdurasuleba AR, Aliev NK, Kakharov AT and Yotdashev Y (1965), Alkylation of cresols with cyclohexanol and cyclopentanol, Zh. Obsh. Khim. 1(3): 517-521.

Abdurasuleva AR, Ismailov N and Yotdashev Y (1969), Alkylation of cresols with cyclohexanol in the presence of KU-2 cation exchanger, Zh. Obsh. Khim. 13(5): $50-52$.

Alam MZ, Alam A, Kamruzzaman M, Kuritha S and Saha M (2008), Development of a mathematical model by means of experimental design for alkylation of $m$-cresol with cyclopentene, Chem. Engg. J Elsevier. 137: 598-602.
Alam A, Alam MZ, Islam STA, Alam S and Saha M (2008), Application of statistical design to benzylation of toluene with benzyl alcohol, Chem. Eng. Technol. 31(3): 417-420.

Belov PS and Isagulyants VI (1964), Alkylation of phenols with cyclic alcohols in the presence of cation exchange resin Ku-2, Zh. Prikl. Khim. 37(11): 2505-2508.

Clausen CA and Matson G (1978), Principles of Industrial Chemistry, (Willey Interscience Publication, New York): 412.

Davies, O.L. Design and Analysis of Industrial Experiments. $2^{\text {nd }}$ Ed. Longman, London, pp. 636.

Filbey AH, Braxton HG and Meltsner BR (1985), Benzylation of phenols with benzyl alcohol. U.S. 4524577 (CI 588-744, C07C391/14), Chemical Abstract. 103.37198s.

Ismailov N (1970), Alkylation of $o$-cresol by cyclic alcohol in the presence of KU-2 cation exchanger, Nauch. Tr. Univ. 37(9): 160-165.

Ismail M, Jamal MS, Islam STA, Asaduzzaman M and Saha M (2007), A mathematical model for the benzylation of p-cresol with benzyl alcohol, Bangladesh J Sci. Ind. Res. 42(2): 187-194.

Lebedev NN (1984), Chemistry and Technology of Basic Organic and Petrochemical Synthesis, Mir. Publishers, Moscow. Vol 1 and 2, pp 638.

Melnikov NN, Baskahov YA and Bokrev KS (1954), Chemistry of herbicides and plant growth regulators. Gkhi. Moscow. 38.

Nemetkin SS, Baskahov YA and Melnikov NN (1951), Synthesis of some alkyl and alkylaryl phenoxyacetic acid, Zh. Obsh. Khim. 12: 2146-2150.

Palma BS, Azim MA, Ismail M, Saha D, Kader MA and Saha M (2007), A mathematical model for the indanylation of $m$-cresol with indene in the presence of benzene sulphonic acid, Bangladesh J Sci. Ind. Res. 42(1): 1-8.

Ravikovich AM (1964), Antioxidants for minerals and synthetic lubricating oils, Chemistry \& Technology of fuels and oils. 11: 64-71. 
Saha M, Jolly YN, Saha D and Sarkar MAB (1997), Alkylation of $p$-cresol with n-alcohols. Bangladesh $J$. Sci. Ind. Res. 32(1): 67-69.

Saha M, Basak PK, Saha D and Alam MZ (2000), Alkylation of $m$-cresol with n-alcohols in the presence of sulphuric acid, Bangladesh J. Sci. Ind. Res. 18(1): 95-102.

Saha M, Saha D, Biiswas S and Zaman MB (1995), Alkylation of $p$-cresol with cyclopentanol, Bangladesh J Sci. Ind. Res. 30(2-3): 21-27.

Shreve RN and Brink JA (1977), Chemical process industries. $4^{\text {th }}$ Ed., (Mcgraw Hill International Book Company, London), p. 814.

Topchiev AV, Zavgorodnil SV and Kryuchkova VG (1964), Alkylation with olefins, Elsevier Publishing company, Amsterdam-London-Newyork, p. 306.

Saha M, Mahmood HMNE, Ghosh SK, Zaman MB, Saha D and Saha SK (2000), Cycloalkylation of $p$-cresol with cycloalkanes in the presence of boronitrifluoride etherate, Bangladesh J Sci. Ind. Res. 18(2): 273-276.

Saha M, Mahmood HMNE, Ghosh SK, Zaman MB, Saha D and Hasan MA (2000), Reaction of $o$-cresol with cyclohexene in the presence of boronitrifluoride etherate, Bangladesh J Sci. Ind. Res. 18(2): 335-337.

Saha M, Moshiuzzaman M and Saha S (1996), Alkylation of $p$-cresol with cyclohexene in the presence of benzene sulphonic acid, Indian J. Chem. Technol. 3: 292-294.

Saha M, Moshiuzzaman M, Saha S and Ghosh SK, (1998), Alkylation of $m$-cresol with cyclohexene in the presence of benzene sulphonic acid, Bangladesh J. Sci. Ind. Res. 33(1): 17-19.

Saha M, Biswas S, Saha SK and Rafique RF (2004), A mathematical model for the alkylation of $p$-cresol with tert.-amylalcohol in the presence of sulphuric acid, Bangladesh J Sci. Ind. Res. 39(3-4): 139-146.

Saha M, Ghosh SK and Saha D (1997), Cyclohexylation of o-cresol, Bangladesh J. Sci. Ind. Res. 32(4): 509-512,-Chem. Abstr. 1998, Vol.129, 244886s.

Saha M, Zaman MB and Nahar N (1994), A study of alkylation of cresols with cyclopentene, Nucl. Sci. Appl. (Dhaka). 3: 19-22, Chem. Abs. 1995, 122, 31043h.
Saha M and Ghosh SK (1989), Cycloalkylation of $m$-cresol, Bangladesh J. Sci. Ind. Res. 7: 273-275.

Saha M, Chowdhury S, Sarkar MAB, Zoly YN and Saha D (1997), A study of alkylation of cresols with cyclooctene, Bangladesh J. Sci. Ind. Res. 32(1): 63-66.

Saha M, Ghosh SK, Saha S and Sarkar MAB (1994), Alkylation of $p$-cresol with cyclohexene in the presence of sulphuric acid, Bangladesh J. Sci. Ind. Res. 29(1): 144-148, Chem. Abstr. 1995, Vol.122, 242714r.

Saha M and Roy RK (1988), Cycloalkylation of $o$-cresol with hexanol, Bangladesh J. Sci. Ind. Res. 6: 73-81.

Saha M and Ghosh SK (1990), Synthesis of 2-tert.-butyl-4-methylphenol, Dhaka University Studies. B 38(2): 197-198.

Saha M and Roy RK (1990), Cycloalkylation of $p$-cresol, $J$. Bangladesh Academy of sciences. 14(1): 127-133.

Saha M and Roy RK (1992), Alkylation of $m$-cresol with cyclohexanol in the presence of sulphuric acid. Bangladesh J. Sci. Ind. Res. 27(3-4): 23-29.

Saha M and Roy RK (1988), Alkylation of $p$-cresol with n-pentanol in the presence of sulphuric acid, Bangladesh J. Sci. Ind. Res. 6: 83-90.

Saha M and Roy RK (1989), Study of alkylation of $p$-cresol with n-hexanol, Bangladesh J. Sci. Ind. Res. 24(1-4): 33-40.

Saha M and Badruzzaman MB (1990), Comparative studies on the reactions of cresols with alcohols in the presence of benzenesulphonic acid, Bangladesh J. Sci. Ind. Res. 8(2): 213-215.

Received: 25 February 2014; Revised: 22 July 2014; Accepted: 25 August 2015. 